\title{
Editorial: ICT and the capability approach
}

\author{
Ilse Oosterlaken $\cdot$ Jeroen van den Hoven
}

Published online: 13 March 2011

(C) The Author(s) 2011. This article is published with open access at Springerlink.com

In discussions about justice, development, well-being and equality, the capability approach $(\mathrm{CA})^{1}$ founded by economist Amartya Sen and philosopher Martha Nussbaum attaches central importance to individual human capabilities. These are the effective freedoms or real opportunities of people to achieve valuable 'beings and doings' (also called 'functionings' by capability theorists). Resourcesincluding technical artifacts-may contribute to the expansion of one's capabilities, but there may also be all sorts of 'conversion factors' in place that prevent this. The approach highlights the 'multidimensionality' of wellbeing and sees people as active agents shaping their own lives. In 1998 Sen won the Nobel Prize in economics for his work, which has deeply influenced the United Nations Development Program (UNDP). In the field of development studies the CA has indeed gained popularity, but this is not the only area of application.

One of the first articles to apply the CA to ICT was-as far as we know - that of Garnham (1997). "Thinking of entitlements in terms of functionings and capabilities", he argued convincingly, "allows us to get behind the superficial indices of access and usage that we so often use" for ICT policy purposes. In the last couple of years an increasing number of scholars seem to discover the potential of the CA for deliberations about ICT. For example, Van den Hoven and Rooksby (2008) acknowledge the profoundness of Sen's critique on the Rawlsian concept of primary goods in their

I. Oosterlaken $(\varangle) \cdot$ J. van den Hoven

Philosophy section, Faculty of Technology, Policy and

Management, Delft University of Technology, P.O. Box 5015,

2600 GA Delft, The Netherlands

e-mail: e.t.oosterlaken@tudelft.nl

J. van den Hoven

e-mail: m.j.vandenhoven@tudelft.nl argument concerning information and distributive justice. And Sen himself has recently (2010) also taken up the topic of ICT, discussing the positive contribution of the mobile phone to the worldwide expansion of human capabilities. Ethics and Information Technology had so far published two articles as part of this growing body of literature: a broad, agenda-setting article (Johnstone 2007) and an application to the digital divide, more in particular websites 'missing' in the South (Wresch 2009).

This special issue now brings together seven new articles on the topic. It contains a mix of theoretical reflections and some applications, and the articles are broadly ordered from the more abstract to the more concrete. The three articles that present the most concrete, detailed cases and that are thus introduced towards the end of this editorial, happen to all focus on 'ICT for Development' (ICT4D). Although of great ethical significance, the topics of poverty and development have so far not been covered in much detail in this journal, and articles on ICT4D tend to be published in specialized journals. $^{2}$ This collection of papers introduces a 'global justice' outlook' that clearly adds to the range of perspectives found in Ethics and Information Technology. Yet as Mark Coeckelbergh rightly notices in his article, "there is nothing intrinsic to the CA that gives us a reason to restrict the scope of the approach to people in developing countries." Let us now briefly introduce each of the articles.

\footnotetext{
1 Two concise, general introductory articles on the capability approach are (a) 'Why the Capability Approach?' by Sabina Alkire and (b) 'The Capability Approach - A Theoretical Survey' by Ingrid Robeyns, both published in issue 1, volume 6 (2005) of the Journal of Human Development.

${ }^{2}$ Like Information Technology \& International Development, The Journal of Information Technology for Development and The Electronic Journal of Information Systems in Developing Countries.
} 
Yingqin Zheng and Bernd Stahl argue that when applying the CA to ICT, insights could be drawn from the field of critical theory, which has a rich history of engaging with technology and ICT. Both perspectives, they argue, share commonalities like a concern for empowerment. One of the things that critical theory has to offer, is an awareness that technology is not value neutral in this respect. Critical theory "provides a more sophisticated and critical account of technology beyond the simplistic notion of goods and resources." If we want to expand human capabilities and agency with the help of ICT, these authors make clear, we should look into the design and regulation of technology. Critical theory, they claim, helps to reveal and address that technology is implied in the distribution of power and sometimes in oppression and therefore possesses "ideological qualities." Yet Zheng and Stahl feel that critical theorists sometimes get stuck in their attempt to "debunk positive myths" about technology. The CA provides a counterpoise to that, "by seeing ICT as means to development and asking questions about what conversion factors need to be in place to facilitate the achievement of potential freedom that technology provides."

Mark Coeckelbergh applies the CA to a topic that may seem to be far from the daily reality of the global poor: ICT and human enhancement. Yet he views this debate (about "changing the capabilities by technological or other means") as not fundamentally different from that about striving for "human development (reaching minimum levels of capabilities)" and "human excellence (maximizing levels of capabilities)." This position is supported by arguments that "human existence is already a humantechnological existence", and has always been so. What we need, according to Coeckelbergh, is "a hermeneutics of techno-human change, involving interpretations of dynamic relations between unstable capabilities, technologies, practices, and values." He thus criticizes the instrumentalism implicitly present in the CA, which sees technologies as mere means to expand universal and timeless capabilities. This obviously ties in with the debate between CA scholars about the validity of Nussbaum's famous list of 10 central human capabilities, which the author addresses towards the end of his article.

William Birdsall proposes a "close collaborative dialogue between the CA and ICT communities", in order to explore "how the real world application of ICT can contribute to expanding specific human capabilities." To facilitate such discourse, he turns to the literature on the 'right to communicate' (RTC). The article meticulously explores the differences and parallels with the CA literature. Although the latter tends to emphasize that capabilities resemble positive freedoms, Birdsall judges that Nussbaum still focuses too much on traditional, negative communication freedoms, like the freedom of speech. It is insufficiently recognized by the $\mathrm{CA}$, the author says, that there is a need for a "re-examination of such traditional rights." Current developments in ICTs, corporate concentration and the social structure of the media, he claims, threaten to make communication predominantly a one-way information flow. This means that people have freedom of speech, but many of them have insufficient capabilities for true communication and participation in societal dialogues. To truly realize the RTC, the CA and ICT community should collaborate and Birdsall ends with some suggestions on the shape this could take.

Mario Toboso addresses the pervasiveness and importance of human diversity, which is a core theme within the literature on the CA. Sen sometimes illustrates the implications of diversity with the example of a bicycle, which may not result in an expanded capability to move about for a disabled person. ${ }^{3}$ Yet "in the realm of ICT", Toboso asserts, "a tradition of 'standard' design for usersanchored in some hypothetical parameters of 'normality' still prevails in product and services development. Not even Internet technologies are free of barriers." In order to expand the capabilities of all people in their full diversity, so the author argues, more attention should be paid to "universal design" and user participation in the design of ICT. To facilitate this change, Toboso proposes to replace the idea of disability, "with its negative connotations", with the more general concept of "functional diversity""describing the reality of persons who have the potential to access the same functionings as other people but in a different way."

Dorothea Kleine notices that the multi-purpose nature of ICT implies that it can in principle contribute a lot to expanding choice and agency, both very important from the perspective of the CA. Yet one of the challenges, she claims, is that the "development industry" is geared towards pre-determined well-being impacts, so in terms of certain ICT usages and human functionings instead of freedoms and capabilities. Furthermore, ICTs themselves may embed certain ideologies and hence there is a danger "that the technology circumscribes the choices of a usercitizen more than that it widens them." Thus it is important to systematically scrutinize ICTs and ICT projects on the basis of the CA. In light of this, Kleine's article addresses the criticism in the general literature that the CA is hard to operationalize. She proposes a framework that could be used "to deconstruct embedded ideologies and analyze the appropriateness of development goals, to map development as a systemic process, and to plan interventions which can result in increased freedom of choice for people." This is

\footnotetext{
${ }^{3}$ Hence, capabilities are considered to be a better evaluative space of justice and equality than resource distribution or access.
} 
illustrated by some concrete cases, including a telecentre in Chile.

Donna Vaughan discusses how ICT4D projects might address the development challenges that aboriginal communities in Australia face. Two case studies are put central in the paper. Her main thesis is that in order to ensure longterm sustainability, it is vital that ICT as resources or inputs are fruitfully connected to ends that are valued by the recipients of such development aid. In the case of these indigenous communities, such valuations are very much influenced by and entangled with the local history and culture-with its emphasis on the community and "caring for country." Hence, Vaughan makes a plea for a contextualized, bottom-up operationalization of the capability approach. Her article links at several points with theoretical debates within the capability approach. One such debate is about the strong focus of the CA on individuals-which has been criticized by some-and about the question if and how the CA should also take collective or group capabilities into consideration.

Finally, Helena Grunfeld presents a rich and detailed evaluation of a Cambodian project giving villagers access to ICT through two central telecentres and several 'village hubs'. What stands out in her case is the large variety of positive changes and benefits for their lives that villagers perceive, going beyond what more common evaluation approaches would identify. The author ascribes these impacts to "the whole project design", taking into account important conversion factors, "rather than just the technology." Grunfeld emphasizes the importance of a longterm perspective when evaluating ICT4D projects, as it takes time to bring about a virtuous spiral, where individuals first acquire "a minimum set of capabilities [...] to make effective use of ICT", which could "in turn strengthen [further] capabilities, empowerment and the ability to maintain sustainable livelihoods."

Together these articles illustrate some of the ways in which the rich literature on the capability approach can be brought to bear on ICT. But they also show that doing so may, in turn, provide input to a range of debates taking place amongst capability theorists. The combination of the CA and ICT offers a promising field for future research, which several people have already started to explore in the past couple of years. Hopefully this special issue sets a milestone that encourages further research. ${ }^{4}$

Open Access This article is distributed under the terms of the Creative Commons Attribution Noncommercial License which permits any noncommercial use, distribution, and reproduction in any medium, provided the original author(s) and source are credited.

\section{References}

Garnham, N. (1997). Amartya Sen's "Capability" Approach to the Evaluation of Welfare: Its Application to Communications. Javnost-The Public, 4(4), 25-34.

Johnstone, J. (2007). Technology as Empowerment: A Capability Approach to Computer Ethics. Ethics and Information Technology, 9(1), 73-87.

Sen, A. (2010). The Mobile and the World. Information Technologies and International Development, 6(special issue), 1-3.

Van den Hoven, J., \& Rooksby, E. (2008). Distributive Justice and the Value of Information: A (Broadly) Rawlsian Approach. In J. Van den Hoven \& J. Weckert (Eds.), Information Technology and Moral Philosophy. Cambridge: Cambridge University Press.

Wresch, W. (2009). Progress on the global digital divide: an ethical perspective based on Amartya Sen's capabilities model. Ethics and Information Technology, 11(4), 255-263.

\footnotetext{
$\overline{4}$ The reader may also be interested in the edited volume 'The Capability Approach, Technology and Design', forthcoming at Springer.
} 